\section{Authors' guardian angels: our 2017 Reviewers of the Year}

\author{
Ruth E Malone
}

As Editor in Chief of Tobacco Control, I regularly speak to junior researchers and novice authors about the publication process and what editors look for in submitted papers. Many novice authors are intimidated by peer review, and lacking good mentorship, they may not showcase their work well in a cover letter, target a journal properly for the type of work they have done, or understand that at high-impact journals, the abstract and cover letter may be the only parts of their paper that are read before the initial screening cut. But they also may seriously misinterpret or underestimate the role of peer reviewers in making their work better.

Many beginning authors think of peer reviewers negatively, as though they have to run the gauntlet and reviewers are people 'out to get' them by finding flaws in their work. While it may feel that way to all of us sometimes, good peer reviewers are also authors' guardian angels, saving them from making errors, pointing out flaws in their logic and helping them see the holes they may have missed filling in because authors are so close to their own work. They are also journals' guardian angels, helping editors in the process of combing through submissions to prioritise what is most important, exciting and innovative in the field.

Each year, Tobacco Control's senior editorial team nominates a set of Reviewers of the Year, who are regarded as outstanding in this important role. There are always multiple nominations, because we have a truly stellar pool of reviewers who care about the quality of the work we publish. Very few among our reviewers fail to produce quality reviews. Unfortunately, while it is an expectation for most academics, reviewing

Correspondence to Professor Ruth E Malone, Social and Behavioral Sciences, University of California, San Francisco, CA 94118, USA; ruth.malone@ucsf.edu is often under-recognised. Our awards are an effort to change that.

Our six Reviewers of the Year for 2017 are, in alphabetical order:

Amanda Amos: A Professor of Health Promotion at the University of Edinburgh and associate editor for tobacco use prevention at Tobacco Control, Dr Amos is a tireless and regular reviewer of a wide range of manuscripts. A respected past member of the senior editorial team until her other responsibilities became too time-consuming, her reviews are thoughtful and detailed and despite being busy, she also honours her commitments to submit reviews on time: the very definition of a reviewer 'good citizen'.

Evan Blecher: Dr Blecher is an economist at the Health Policy Center at the University of Illinois at Chicago and an Honorary Associate Professor in the School of Economics, University of Cape Town. He is among our true workhorse reviewers, having accepted almost one review per month during the last year. He is, according to the nominator, 'very reliable and always has useful comments.'

Gary Giovino: Dr Giovino is a longserving reviewer, and a go-to person when we are struggling to find reviewers for a paper. A Professor and Chair of the Department of Community Health and Health Behavior in the School of Public Health at University of Buffalo, he also serves on Tobacco Control's Editorial Advisory Board and accepts almost every review invitation. His reviews are characterised by timely turnaround, exquisite sensitivity to authors and consideration of how the work may be made relevant for our international readership.

Alex Liber: Mr Liber is a data analyst with the Economic and Health Policy Research Program at the American Cancer Society. His nominating senior editor was impressed by the unusual effort he made to illustrate an important analytic point for the authors of a paper he reviewed. $\mathrm{He}$ actually created an illustrative data set to demonstrate how his recommendations for an alternative analysis could be useful.

Wendy Max: Dr Max is Professor of Health Economics and Director of the Institute for Health and Aging in the School of Nursing, University of California, San Francisco. The nominating senior editor credited her with contributing an especially detailed and thorough review of a complex paper by authors whose first language was not English: 'her review was very constructive and clearly aimed at helping them strengthen their work, rather than just listing limitations.' This skill, of helping authors see how to address critique, not merely providing a list of weaknesses, distinguishes all our honoured reviewers.

Patricia McDaniel: An Associate Professor in the Department of Social and Behavioral Sciences at University of California, San Francisco, Dr McDaniel was characterised by the senior editor who nominated her as 'the quality and quantity winner. The case that stands out for me is that she did the legwork of reading original references to clarify the underlying methods for a study that reported secondary analyses. Like an investigative reporter searching for missing details and more context, this extra work from a reviewer made a paper much clearer and better.'

Warm congratulations to our honoured colleagues, and thanks again to all who have contributed their time and expertise to the journal.

Funding None declared.

Competing interests None declared.

Patient consent Not required.

Provenance and peer review Not commissioned; internally peer reviewed.

(C) Article author(s) (or their employer(s) unless otherwise stated in the text of the article) 2018. All rights reserved. No commercial use is permitted unless otherwise expressly granted.

\section{Check for updates}

To cite Malone RE. Tob Control 2018;27:245.

Tob Control 2018;27:245.

doi:10.1136/tobaccocontrol-2018-054416 